\title{
LA ORTODOXIA ECONÓMICA DESALIENTA EL ESTUDIO DEL COMPORTAMIENTO COLECTIVO
}

Hendrik van den Berg*

E1 homo ceconomicus, tal como lo concibe la ortodoxia económica, es una especie de monstruo antropológico: este hombre práctico de mentalidad teórica es la personificación extrema de la falacia escolástica, un error intelectualista muy común en ciencias sociales, por el cual el estudioso pone en la cabeza de los agentes que estudia -amas de casa u hogares, empresas o empresarios, etc.- las consideraciones y construcciones teóricas que él tuvo que elaborar para explicar sus prácticas.

Pierre Bourdieu (2005b, 209).

$\mathrm{L}$ os economistas tradicionales de los países occidentales usan casi exclusivamente modelos neoclásicos en su trabajo. Estos modelos suelen suponer que los agentes económicos son individuos racionales que solo consideran su propio bienestar material cuando toman decisiones económicas. E1 beneficio práctico de este supuesto es que la actividad económica agregada se puede describir como la suma matemática de sus componentes; por supuesto, suponiendo también que el sistema se mantiene sin cambios. A menudo dichos modelos se reducen a modelos de un agente representativo, en los que la persona promedio, u homo ceconomicus en la cita de Bourdieu, representa el comportamiento económico agregado. Esta estrategia de modelación recuerda la frase de Margaret Thatcher: "no hay sociedad, solo individuos". Este enfoque de la modelación económica no solo dificulta el análisis del comportamiento económico de las

* Profesor de Economía en la Universidad de Nebraska, Lincoln, y profesor adjunto en la Universidad de Missouri, Kansas City, [Hvan-den-berg1@unl. edu]. Esta traducción, de Alberto Supelano, se publica con las autorizaciones correspondientes. Fecha de recepción: 10 de marzo de 2015, fecha de aceptación: 29 de abril de 2015. Sugerencia de citación: van den Berg, H. "La ortodoxia económica desalienta el estudio del comportamiento colectivo", Revista de Economía Institucional 17, 32, 2015, pp. 13-37. DOI: 10.18601/01245996.v17n32.01 
organizaciones y otras formas de comportamiento de grupo, sino que también lleva a una representación errónea del comportamiento real de las personas.

El supuesto de que los seres humanos actúan y toman decisiones en aislamiento no es consistente con lo que los psicólogos, sociólogos, politólogos economistas del comportamiento y otros científicos sociales saben del comportamiento humano. Hay abundante evidencia de que los humanos son animales de grupo que muestran sentimientos hacia otros, como la envidia y la empatía, y establecen variadas relaciones sociales. Los humanos no son aislacionistas. Uno de los costos del error intelectual de poner a un homo ceconomicus individualista y egocéntrico irreal en el centro del análisis es que impide analizar el importante rol económico de los grupos y las organizaciones. El comportamiento de empresas, sindicatos, entidades del gobierno y grupos de cabildeo, entre muchas otras organizaciones, no se puede explicar como la suma de las acciones de sus miembros. Además, el énfasis en el individuo dificulta el análisis del desarrollo de fenómenos sociales como las instituciones y la cultura. De acuerdo con el pensamiento económico tradicional no hay una cultura de grupo, solo un comportamiento individual racional egocéntrico. Por ello, aunque reconozcan la importancia de la cultura y otras instituciones formales en la formación del comportamiento económico, los economistas tradicionales suelen introducir estos fenómenos de grupo en sus modelos como variables exógenas a las que se supone que los individuos se ajustan de manera racional, así como se ajustan a otras variables exógenas y endógenas.

Este artículo intenta explicar por qué la economía restringe el alcance de su análisis hasta tal punto que sus seguidores ignoran o, a lo sumo, especifican mal los roles económicos de grupos y organizaciones claramente identificables así como fenómenos de grupo como la cultura. Argumenta que la explicación está en el campo de la cultura, uno de esos fenómenos de grupo que los economistas tradicionales no pueden tratar fácilmente. Psicólogos, economistas del comportamiento y neurocientíficos, entre otros, han documentado cómo se desarrollan las culturas humanas para enfrentar la extraordinaria complejidad de su existencia. En suma, fenómenos de grupo como las instituciones y la cultura son endógenos en la toma de decisiones y, por tanto, en todo comportamiento económico. Aunque la cultura contribuye a establecer pautas comunes de comportamiento que ayudan a las personas a enfrentar su vida cotidiana, también puede distorsionar la realidad e inducirlas a errores. La cultura de la economía es un buen ejemplo, 
porque lleva a ignorar importantes asuntos económicos relacionados con las organizaciones y los fenómenos de grupo.

Este artículo recurre a otras disciplinas, especialmente a la sociología, para explicar la cultura de la economía. En particular, la obra del sociólogo francés Pierre Bourdieu proporciona un marco útil para entender por qué los economistas desarrollaron y mantienen una cultura que dificulta el estudio de las causas y consecuencias del comportamiento organizado de grupo. Finaliza con algunos comentarios acerca de cómo pueden librarse de su cultura restrictiva y estudiar más eficazmente las organizaciones que desempeñan un rol tan dominante en la economía actual. Será muy difícil que la economía escape de su cultura individualista bien establecida, en especial porque esta impide que los economistas reconozcan seriamente las deficiencias de su cultura.

\section{BREVE MIRADA A LA HISTORIA DEL PENSAMIENTO ECONÓMICO}

Una importante barrera para entender mejor el comportamiento de grupo y el papel económico de las organizaciones es la aceptación de la defectuosa estrategia de modelación conocida como reduccionismo cientifico. Este enfoque supone que es posible entender la totalidad del sistema analizando sus partes en forma aislada. Al adoptar el reduccionismo científico, los economistas ignoran la posibilidad de que el sistema económico en su conjunto o grandes sectores de la economía produzcan resultados que no solo dependen de las partes sino también de cómo interactúan esas partes. Así, ignoran la posibilidad de que algunos sistemas económicos puedan funcionar mejor que otros aunque tengan conjuntos similares de personas y de recursos naturales que pueden utilizar.

La aceptación general del reduccionismo científico data de la última mitad del siglo XIX, cuando los economistas empezaron a centrarse en la asignación de recursos dentro de los estrechos límites del sector de mercado de la economía. Empezaron a suponer, como sigue suponiendo la mayoría de los economistas tradicionales o neoclásicos ortodoxos, que una buena comprensión del sector de mercado era suficiente para diseñar políticas económicas e instituciones. No solo se ignoraron las actividades del hogar, la interacción con la naturaleza y otras actividades ajenas al mercado, sino que el potencial de auges y quiebras sistémicas fue excluido en los modelos neoclásicos que postulaban funciones suavizadas y equilibrios estables dentro de un sistema estático e invariable. 
E1 libro de texto más vendido a comienzos de la década de 1890 fue Principios de Economía de Marshall, cuya octava edición se publicó en 1920. Aunque Marshall reconoció de pasada muchos aspectos de la complejidad económica, la estrategia de modelación reduccionista dominante en su libro de texto estableció el paradigma neoclásico que aún predomina en la economía tradicional. De especial importancia histórica es el modelo de Walras (1874), que especificó la economía como un gran sistema de ecuaciones, una para la demanda y una para la oferta en cada uno de los millones de mercados donde los consumidores compraban bienes y servicios a los productores, los gobiernos compraban bienes y servicios a los productores, los productores compraban bienes de capital a otros productores, los productores compraban trabajo a los individuos y los productores tomaban en alquiler tierras a sus propietarios. El sistema de Walras tenía $m$ productos, $m$ precios de productos, $m$ cantidades de productos, $n$ factores de producción, $n$ precios de factores, $n$ cantidades de factores y $m n$ coeficientes técnicos. En general, un sistema de ecuaciones lineales se puede resolver si el número de incógnitas es igual al número de ecuaciones, y Walras satisfizo ese requisito. Pero el modelo era demasiado grande para usarlo realmente en el análisis práctico.

Este enorme modelo matemático parecía reflejar la complejidad de un sistema económico en el que todas las partes estaban conectadas entre sí. Pero, para proyectar la idea de que la economía era un sistema estable y solucionable, Walras supuso un sistema de ecuaciones lineales con parámetros fijos, lo que implicaba que las relaciones entre sus componentes no podían variar. Por ello, su modelo no representaba un sistema económico realista en el que las variaciones de los componentes y de las relaciones entre ellos cambian con el tiempo. Y, como Walras eligió a los individuos como actores de su sistema lineal y aditivo de mercados, se descartó la formación de grupos independientes y únicos, y de organizaciones de consumidores, productores, trabajadores, etc.

Irónicamente, debido a que los economistas aceptaron intuitivamente que había una solución para este sistema de ecuaciones pero no podían aplicar realmente el enorme modelo walrasiano para abordar problemas prácticos, se sintieron justificados para centrarse en mercados individuales e ignorar las interconexiones dentro de todo el sistema. Esta inclinación al reduccionismo científico revivió incluso la metáfora de la mano invisible de Smith (1776), que sugería que si los $m n$ mercados individuales funcionan bien los resultados generales son socialmente óptimos. Las ideas asociadas con Walras, 
Marshall y otros economistas de finales del siglo XIX que aceptaron implícitamente el reduccionismo científico junto con el papel central del individuo racional se conocen como escuela neoclásica.

La tendencia al reduccionismo científico en economía se revirtió súbitamente en la década de 1930, cuando la economía mundial se hundió en la Gran Depresión. Quedó en claro que el sistema económico no era estable ni constante y que el mismo conjunto de personas, máquinas, infraestructura y recursos naturales produjo resultados muy diferentes en 1929 y 1930 . Durante varias décadas, las políticas macroeconómicas fueron influidas por la Teoría general del empleo, el interés y el dinero de Keynes (1936), una obra que contradecía la mano invisible al mostrar por qué las interacciones sistémicas entre diferentes grupos sociales podía provocar y mantener recesiones y depresiones económicas. El análisis keynesiano también sugería que la acción de grupos distintivos de actores económicos tenía grandes efectos sobre el sistema económico en su conjunto y, por tanto, en el bienestar de cada integrante. Las políticas macroeconómicas activas de las organizaciones del gobierno para contrarrestar esas tendencias eran ampliamente aceptadas.

\section{LATEORÍA ECONÓMICA TRADICIONAL CONTEMPORÁNEA}

Pero la revolución keynesiana tuvo corta vida. En la segunda mitad del siglo XX las ideas keynesianas fueron marginadas en favor de versiones más sofisticadas del modelo reduccionista walrasiano. Esta marginación puede haber sido inducida en parte por concepciones erróneas del funcionamiento del sistema económico. Por ejemplo, el periodo de finales de la Segunda Guerra Mundial hasta comienzos de los años setenta, cuando se experimentó el crecimiento económico material más rápido de la historia humana, rara vez se interpretó como un éxito de las políticas macroeconómicas activas del gobierno y sí como una prueba de que el sistema de libre mercado crecería consistentemente si se dejaba operar por sí solo. Además, parecía que los economistas había reconocido el error de su reduccionismo científico prekeynesiano cuando empezaron a elaborar modelos macro-micro que unían sistemáticamente a los consumidores, trabajadores, productores, banqueros e inversionistas al desempeño agregado de la economía. Los macroeconomistas decían que estaban estableciendo los microfundamentos de la macroeconomía.

Pero, en la práctica, se requerían supuestos simplificadores muy fuertes para construir modelos macroeconómicos manejables lógicamente compatibles con los modelos microeconómicos del com- 
portamiento individual y de la firma. De modo que la búsqueda de microfundamentos no parece haber logrado más que proporcionar justificaciones matemáticas de modelos irreales de comportamiento individual que se podían ligar a modelos macroeconómicos igualmente irreales. Los mercados de trabajo se solían modelar como mercados competitivos donde se pagaba al trabajo su producto marginal. Esos modelos no podían abordar fenómenos económicos reales como la existencia de sindicatos, salarios de eficiencia y compensaciones para motivar a los trabajadores, costos fijos por contratar y despedir trabajadores, trabajadores desempleados y subempleados en casi todas las economías, y alianzas políticas para tratar esos asuntos.

Además, se suponía que todos los productores enfrentaban costos crecientes para mantener el supuesto de competencia perfecta en los modelos. Los altos niveles de concentración industrial, para no mencionar la evidente ubicuidad de oligopolios y cuasi monopolios, socavan la legitimidad de los modelos que suponen competencia perfecta. Se ignoraban las externalidades apelando a una mala interpretación del teorema de Coase (1960), a saber, que personas, firmas y gobiernos están suficientemente informados y motivados para encontrar maneras de negociar la parte mutuamente benéfica de los costos o beneficios externos. Los mercados financieros se incorporaron en los modelos adoptando el conveniente esquema de mercados eficientes de Fama (1970), el cual supone que toda la información disponible está incorporada en los precios de los activos, y la hipótesis de que la especulación estabiliza los mercados financieros de Friedman (1953). Más tarde, la definición de expectativas racionales de Muth (1960) fue incorporada en los modelos macroeconómicos por Lucas (1972) para explicar por qué el gobierno no podía manejar la economía de un modo que mejorara los resultados económicos. Las quiebras financieras que Keynes asoció a la incertidumbre financiera fueron dejadas de lado por el trabajo teórico de Arrow y Debreu (1954) y Debreu (1959), quienes simplemente substituyeron la incertidumbre de Keynes por la palabra riesgo y la definieron en términos de distribuciones de probabilidad conocidas; luego se supuso la existencia de un conjunto de mercados competitivos de bienes contingentes que permitían asegurar o diversificar todos los riesgos. Debreu escribió quizá seriamente: "Esta nueva definición de bien permite obtener una teoría de la incertidumbre libre de todo concepto de probabilidad y formalmente idéntica a la teoría de la certeza" $(1959,98)$. La regulación financiera era así innecesaria, y las innovaciones financieras, como las que hundieron la economía global en 2008, se veían 
positivamente porque eran adiciones a los mercados contingentes y ayudaban a estabilizar el sistema económico.

La aversión de los economistas ortodoxos a aceptar la necesidad de una mayor regulación y una reorganización financiera después del colapso financiero global de 2008-2009 indica que siguen ignorando cómo se comportan las organizaciones financieras y que ese comportamiento genera colapsos financieros costosos, es decir, resultados no lineales. La aguda alza de las ganancias corporativas y la distribución del ingreso cada vez más desigual que caracteriza a economías como las de Estados Unidos y el Reino Unido indican, además, que las empresas de negocios no se describen exactamente con los supuestos de los modelos neoclásicos. Por ejemplo, los economistas ortodoxos a menudo simplemente suponen que se cumplen las condiciones especiales que Jensen y Meckling (1976) demostraron que eran necesarias para que los gerentes de las empresas privadas actuaran como fieles servidores de los accionistas, las cuales incluyen altos niveles de competencia y plena información de los accionistas. Junto a los supuestos de competencia perfecta y plena información, citan a Jensen y Meckling para argumentar que las grandes corporaciones actúan de un modo que promueve el bienestar general de la sociedad. Es claro que las grandes empresas de negocios se pueden comportar de maneras que no reflejan los deseos y los intereses de trabajadores, accionistas u otros grupos de personas. Y que los modelos que suponen mercados competitivos y plenamente informados en los que individuos egoístas toman decisiones racionales y plenamente informadas no pueden explicar la corrupción y el activismo político de las empresas de negocios, la unión de trabajadores en sindicatos, la demanda de servicios proporcionados colectivamente por el gobierno ni las grandes cantidades de dinero que se gastan en cabildeo.

\section{EL PROGRESO CIENTÍFICO}

El uso persistente de un marco de modelación que no explica exactamente ni predice eventos económicos claramente observables es contrario a la ciencia. Sin embargo, la economía no es el primer campo que viola el método científico. En su análisis de la historia de la ciencia, Thomas Kuhn observó que "la ciencia no tiende al ideal que sugiere nuestra imagen de su acumulación. Quizá sea otro tipo de empresa" $(1962,2)$. Y señaló, en cambio, que a lo largo de la historia los pequeños avances científicos a menudo seguían trayectorias acumulativas sistémicas pero los cambios científicos verdaderamente revolucionarios, mucho menos frecuentes, eran inconmensurables con 
el conocimiento anterior y carecían incluso de un patrón de medida común. Los axiomas, o verdades comunes aceptadas, a menudo diferían entre los principales científicos. Kuhn llamó cambio de paradigma a la ciencia revolucionaria, a la que entendía como una nueva manera de observar el mundo, analizar la evidencia e interpretar las conclusiones. En economía a menudo llamamos paradigma a una escuela de pensamiento.

La palabra paradigma proviene del término griego paradeigma, que significa "pauta". La neurociencia, la psicología y la economía del comportamiento, entre otros campos, muestran que el cerebro humano es muy consciente de las pautas, y que intenta encajar todo lo que ve en pautas familiares. Estas pautas, a menudo incorporadas en historias, ceremonias, procedimientos, organización social y normas sociales, pasan a formar parte de la cultura de un grupo. Esta cultura dice a sus seguidores qué deben o no estudiar, a qué tipo de preguntas deben buscar respuesta e incluso cómo deben interpretar sus resultados. La investigación interdisciplinaria muestra que la cultura tiende a auto reforzarse, lo que explica por qué los paradigmas a menudo persisten pese a las claras anomalías que no encajan en las pautas que prescriben. La persistencia injustificada de un paradigma se vuelve aún más probable si, como sucede en economía, la cultura de grupo desalienta a reconocer explícitamente fenómenos de grupo como la cultura de grupo.

\section{LOS ORÍGENES DE LA CULTURA}

La cultura consiste en el conjunto de pautas comunes de actividad y comportamiento humano que las personas valoran y con las que se identifican. En forma más específica, la Unesco la define así:

la cultura se debe considerar como el conjunto distintivo de características espirituales, materiales, intelectuales y emocionales de una sociedad o grupo social, que abarca, además del arte y la literatura, los estilos de vida, las maneras de vivir juntos, los sistemas de valores, las tradiciones y las creencias (Unesco, 2002).

La cultura está compuesta por instituciones informales: tradiciones, mitos, religiones, normas de comportamiento, costumbres, expresiones artísticas y símbolos. Y surgió en el proceso de la evolución humana porque permitió hacer frente a la complejidad creciente de la existencia. En esencia, la cultura ayuda a aumentar la cohesión social induciendo a los individuos, que piensan independientemente pero tienen inclinaciones sociales, a conformarse a las pautas reconocidas por quienes comparten la misma cultura. Cuando se describe la cultura 
de la economía es claro que los modelos que los economistas usan comúnmente para explicar sus asuntos y transmitir sus ideas forman parte de la cultura de su campo.

Es tentador interpretar el desarrollo humano como un proceso en el que las personas se vuelven cada vez más capaces de pensar racionalmente y actuar sin las tradiciones, hábitos y normas intrínsecamente irracionales que constituyen la cultura. El homo ceconomicus individualista y racional es la conclusión lógica extrema de esa interpretación. Seabright (2010) resalta, de hecho, la capacidad humana para el pensamiento abstracto como una razón importante del éxito de la humanidad como especie en el corto plazo. Pero también señala que los humanos usaron su capacidad mental en formas prácticas que no concuerdan con la definición de racionalidad de la economía moderna porque la vida es demasiado compleja y limitada en el tiempo para que los humanos deliberen cada acción. Los economistas del comportamiento sugieren que siguen estrategias más realistas. Por ejemplo, Simon (1955) usó experimentos para demostrar que tienden a tomar atajos y a lograr "satisfacción", y Simon (1959) demostró que las personas hacen lo mejor que pueden, pero que solo son "limitadamente racionales" porque deben tomar decisiones rápidamente y sin todos los hechos a la mano.

E1 historiador económico y economista neoinstitucional North describe así los orígenes de la cultura:

En la historia humana siempre ha habido un gran residuo que desafía la explicación racional; un residuo que se ha de explicar en parte mediante elementos no racionales encarnados en la brujería, la magia y las religiones; y en parte mediante un comportamiento no racional más prosaico caracterizado por dogmas, prejuicios y teorías "mal concebidas". De hecho, a pesar de la [...] afirmación de eminentes teóricos de que no es posible teorizar frente a la incertidumbre, los humanos lo hacen todo el tiempo; sus esfuerzos van desde afirmaciones ad hoc y creencias laxamente estructuradas, como las que cobijan los términos "conservadoras" y "liberales", hasta elegantes ideologías sistemáticas como el marxismo o las religiones organizadas (2005, 15-16).

Keynes (1936) llamó “convenciones” a estas teorías mal concebidas, porque a falta de algo mejor algunas ideas parecen proporcionar una guía razonable para la acción que luego se convierte en una forma convencional de hacer las cosas. En el capítulo 12 de su Teoría General comparó a los innovadores con los exploradores del Polo Sur, que en un estado de incertidumbre recurrieron a sus espiritus animales para decidir cuándo seguir adelante y cuándo ser cautelosos. Langlois $(1986,1992)$ se refiere a las ideas no comprobadas pero convenientes de North como "reglas sociales", y a la creación implícita de instituciones sociales en un grupo como una forma colectiva de "hacer reglas". 
Los científicos sociales consideran que la cultura está constituida por "ideas poco meditadas", "creencias laxamente estructuradas", "convenciones" "reglas sociales".

La investigación en neurociencia también proporciona evidencia de que el ser humano no funciona como postula Muth (1960). Churchland explica con precisión los hallazgos de la neurociencia:

Las primeras capacidades de auto representación del cerebro aparecieron cuando
la evolución encontró soluciones neurales de red para coordinarse y regular las
señales internas del cuerpo, lo que mejoró las estrategias de comportamiento.
La flexibilidad adicional para organizar opciones de comportamiento cohe-
rentes surge de modelos neurales que representan algunos estados internos
del cerebro como estados del cuerpo y otras señales como percepciones del
mundo externo. Los cerebros manipulan los modelos internos para predecir
las distintas consecuencias de distintas opciones de comportamiento en el
mundo externo (2002, 308).

Usando ese método, científicos como Lebeouf (2002) y Medin y Bazerman (1999), entre muchos otros investigadores, han confirmado que los procesos automáticos y emocionales del cerebro humano dependen en gran medida del reconocimiento de pautas. Sus experimentos muestran que el cerebro se agita cuando surgen pautas no familiares o no puede encontrar pautas familiares en lo que está observando. Pero es necesario señalar que, como demuestran los experimentos reportados en Frederick (2005), incluso las personas más inteligentes malinterpretan rutinariamente un problema o una observación porque lo encajan en una pauta familiar que, de hecho, no se aplica exactamente al problema entre manos. Al confiar en pautas, las personas cometen errores.

E1 cerebro humano evolucionó entonces no solo para usar el razonamiento abstracto cuando trata asuntos complejos sino para inferir reglas prácticas que guíen la acción en esa realidad compleja. Se requerían reacciones rápidas para enfrentar depredadores y desastres naturales inesperados; la larga deliberación no era una manera práctica de enfrentar al oso que aparecía súbitamente en la entrada de la caverna.

Pero la humanidad no sobrevivió tan solo por combinaciones prácticas de pensamiento abstracto y atajos inteligentes; sobrevivió porque también mantuvo grupos cohesionados cuyos miembros podían interactuar eficazmente para lograr resultados sociales más grandes que los que podía lograr la simple suma de acciones individuales. La evolución de los humanos en animales de grupo refleja la seguridad de los números, la eficiencia de la división de tareas, los beneficios de compartir el conocimiento y la capacidad para llevar a cabo grandes proyectos. Al dar importancia a las afirmaciones compartidas y a las 
creencias mutuas, los humanos pudieron suprimir algunos de los pensamientos independientes y acciones individuales perjudiciales para la supervivencia de sus grupos sociales. Un propósito fundamental de la cultura fue, entonces, mantener la cohesión de grupo frente a amenazas externas.

En suma, la cultura hace posible que las sociedades humanas sobrevivan dentro de las restricciones de su entorno económico, social y natural. La historia sugiere que la cultura humana no siempre logra el objetivo fundamental de la supervivencia. Ha habido muchos conflictos entre individuos y entre grupos de individuos. $\mathrm{Y}$ numerosas civilizaciones se derrumbaron porque no pudieron enfrentar los retos sociales y naturales que enfrentaron. En conjunto, sin embargo, la cultura humana ha tenido mucho éxito en cuanto ha hecho posible que los humanos, en un breve periodo evolutivo de tiempo, tengan gran presencia en la Tierra.

Infortunadamente, los economistas no han hecho una buena tarea al analizar el comportamiento de grupo y organizacional que hizo posible este éxito evolutivo. Cabe señalar que la teoría moderna del crecimiento que se suele emplear para analizar el rápido desarrollo económico del siglo XX está firmemente arraigada en la estructura de modelación neoclásica, una estructura que niega el desarrollo de fenómenos de grupo como la cultura.

\section{LA CULTURA Y LA NECESIDAD DE REFLEXIVIDAD}

E1 sociólogo francés Pierre Bourdieu presenta ideas muy útiles para entender por qué persisten la escuela neoclásica y su estrategia de modelación basada en el individualismo y el interés propio a pesar de la abundante evidencia que contradice sus conclusiones. Bourdieu es bien conocido por instar a sus colegas sociólogos a emprender un análisis autocrítico sistemático y riguroso de la manera en que su campo estudia la cultura. Bourdieu llama reflexividad a dicho autoanálisis (1977a, 1988, 1989a, 1990, 2005a) ${ }^{1}$. Sus largos años de estudio acerca de cómo la cultura perpetuó estructuras sociales injustas y opresivas lo llevaron a concluir que los sociólogos muy a menudo dejan que su propia cultura sesgue sus análisis e interpretaciones de otras culturas. Señaló que los sociólogos debían saber mejor que nadie que la cultura distorsiona la percepción de la realidad, y desafió a sus colegas a desarrollar una "sociología de la sociología" para entender mejor su propios sesgos. Quizá los economistas deberían seguir la

\footnotetext{
${ }^{1}$ Ver también las discusiones sobre reflexividad en Wacquant (1989) y Bourdieu y Wacquant (1992).
}

Revista de Economía Institucional, vol. i7, n.o 32, Primer semestre/20i5, Pp. I3-37 
sugerencia de Bourdieu y ser más conscientes de que la cultura de su campo restringe su análisis. Lo que sigue es una breve sociología de la economía que usa al marco de Bourdieu para analizar la cultura.

\section{LA SOCIOLOGÍA DE LA ECONOMÍA}

Bourdieu toma como punto de partida la obra del sociólogo de comienzos del siglo XX Max Weber (1978), quien reconoció que las personas generalmente se adhieren a más de una cultura porque su posición en la sociedad a menudo rebasa los conceptos tradicionales de clase o cultura. Profesiones como la sociología o la economía desarrollan fuertes subculturas que son adoptadas por adherentes que viven a la vez en culturas nacionales y étnicas diferentes. Esta adhesión a diversas culturas es importante para entender la amplia aceptación del análisis neoclásico entre economistas de todo el mundo; la subcultura de la economía puede sobrevivir dentro de culturas nacionales y étnicas distintas.

El primer concepto analítico de Bourdieu es el de campo, que define como la arena social o intelectual en la cual las personas pasan buena parte del día y pueden perseguir mejor sus principales intereses económicos y sociales. Las personas normalmente se identifican con culturas nacionales o étnicas generales, pero en sus actividades diarias tienden a prestar mayor atención a su entorno profesional o social inmediato. Muchas se identifican estrechamente con la cultura de un empleo o industria particular, o del entorno de trabajo al que dedican gran parte de su tiempo y de su esfuerzo. Para los académicos, el término campo es claro porque dedican la mayor parte de su vida a un campo intelectual bien definido. Cabe señalar, sin embargo, que el concepto de campo de Bourdieu es más general. Por ejemplo, los adolescentes tienden a adoptar la cultura de su entorno escolar y de las nuevas relaciones sociales que establecen allí. Los miembros del ejército adoptan una cultura militar distintiva de jerarquía, obediencia y violencia. Y los atletas, una cultura que quizá incluye reglas específicas, normas y perspectivas sobre el entrenamiento repetitivo, la proeza física, la competencia y, dependiendo del deporte, un comportamiento agresivo.

Cada individuo suele pasar gran parte del tiempo centrado en su campo porque es allí donde se juzga su éxito en la vida. Por ejemplo, un adolescente puede chocar con la cultura de su hogar e incluso de su nación, pero ir a la escuela con ropas que chocan con la cultura de su escuela sería inconcebible. En forma similar, los economistas provienen de diversas culturas nacionales, étnicas y sociales, pero como 
es evidente para quien asiste a una conferencia internacional, todos se visten, actúan, hablan y presentan investigaciones que usan modelos, métodos y expresiones muy similares. Casi todos tienden a juzgar a sus colegas con el mismo conjunto de criterios que cubren los temas, métodos y procedimientos que se consideran apropiados en su campo.

Bourdieu desarrolla dos conceptos que ayudan a describir de modo más preciso la cultura de un campo. Primero, los miembros de un campo adoptan ciertas actitudes, comportamientos y disposiciones a los que Bourdieu llama habitus, un término que toma de los escritos de Aristóteles y Max Weber. El habitus es un conjunto de percepciones, costumbres, convenciones, normas, manierismos, comportamientos, expresiones y métodos subjetivos pero persistentes que los miembros del campo consideran adecuados o "normales". Incluye la disposición de una persona hacia otras y los comportamientos que piensa que otros miembros del campo usarán para juzgar si es uno de ellos. Bourdieu rebasa el largo debate sociológico entre subjetividad y objetividad definiendo el campo como algo objetivo y el habitus como algo subjetivo; y argumenta que las personas desarrollan las disposiciones y actitudes subjetivas de su habitus para tener éxito en su campo objetivo bien definido.

Por ello es probable que un soldado adopte un habitus caracterizado por la inclinación al comportamiento agresivo, la aceptación incondicional de la autoridad y el rango, y la fuerte afirmación de la lealtad de grupo. El habitus de un hombre de negocios tiende a caracterizarse por una admiración de la agresividad en las ventas, el desdén por las restricciones del gobierno a la actividad empresarial y la respuesta positiva a recompensas monetarias. Es muy probable que el habitus de un economista incluya el uso de modelos neoclásicos para analizar los asuntos desde la óptica de la economía de mercado, la preferencia por las matemáticas al enunciar hipótesis, la familiaridad con métodos estadísticos y la renuencia a abordar temas que van más allá de la economía de mercado o, Dios nos libre, otras disciplinas. Recordemos nuestro análisis general de la cultura y del comportamiento de grupo; la incursión en otras disciplinas se tiende a considerar como deslealtad con la cultura propia, y esa deslealtad puede debilitar la cohesión del grupo. Por ello, las ideas externas se toman a burla instintivamente, pero los modelos y métodos que encajan en el marco del habitus neoclásico rara vez se critican desde dentro.

Bourdieu muestra que hay un conflicto inherente entre la realidad del campo propio y el carácter arbitrario de gran parte de lo 
que comprende el habitus de ese campo. Psicológicamente, es difícil que una persona inteligente enfrente esta combinación de un campo objetivo y un habitus subjetivo. Por ello, las sociedades humanas, sus grupos y organizaciones y sus campos crean, en gran parte inconscientemente, conjuntos de creencias, símbolos e historias populares que justifican el habitus subjetivo y algo arbitrario asociado al campo objetivo personal. Bourdieu llama doxa a los conjuntos de creencias, historias y filosofías bien establecidas pero no comprobadas. Estos incluyen dogmas religiosos, filosofías sociales generales y opiniones políticas asociadas ampliamente aceptadas pero no comprobadas. La doxa proporciona las pautas generales que usan las personas para juzgar su comportamiento en su campo, y el comportamiento de otras personas en su campo y en otros campos.

La doxa de un campo incluye las "ideas poco meditadas" que en opinión de North fueron construcciones sociales que hicieron posible que las personas y sociedades afrontaran las complejidades mal entendidas que enfrentaban rutinariamente. En conjunto, el habitus y la doxa en que se apoya constituyen lo que llamamos cultura.

Se podría decir que la doxa que está en la base del habitus de la economía es la doctrina neoliberal. Como muestra en detalle Harvey (2005), este conjunto de creencias incluye la caracterización de los seres humanos como agentes siempre racionales y científicamente objetivos cuando toman decisiones ${ }^{2}$. También incluye la creencia de que la "economía" se puede modelar como un sistema de mercados competitivos en el que la "mano invisible" transforma el comportamiento individual egoísta en un estado óptimo de bienestar general. Los pensadores neoliberales argumentan que el libre mercado es esencial para lograr el importante objetivo social de dar a los individuos "libertad de elegir". Creen que los mercados dan mayor libertad y mejores opciones que los programas "coactivos" del gobierno y los regímenes de regulación. El neoliberalismo también tiene un fuerte sesgo contra la acción colectiva y en favor de la empresa privada. Finalmente, la doxa de la economía pone el bienestar individual en el centro y en el primer lugar, hasta el punto de sugerir que toda forma de acción colectiva es necesariamente coercitiva y que, por ello, siempre reduce el bienestar.

Las políticas que el Fondo Monetario Internacional impuso a muchas economías endeudadas después de la crisis de la deuda de 1982, conocidas como el Consenso de Washington, eran un reflejo

\footnotetext{
${ }^{2}$ Bourdieu (2005b) y Wacquant (2009) muestran explícitamente que la doxa de la economía es consistente con las ideas neoliberales.
} 
directo de esta doxa, e incluían: libre comercio, privatización de activos del gobierno, políticas monetarias conservadoras para reducir la inflación, presupuestos balanceados del gobierno, eliminación de las reglas del mercado de trabajo y menor regulación del mercado financiero. Las políticas de austeridad que hoy se imponen a países endeudados de la Unión Europea - como Grecia e Irlanda- son otro reflejo del consenso de Washington y su doxa neoliberal. No es claro que esas políticas hayan mejorado realmente el bienestar humano en alguna parte, $y$ no obstante se les da un tratamiento favorable en los libros de texto y en muchas investigaciones, sin suscitar mucho debate entre los economistas tradicionales. La función de la doxa no es, por supuesto, suscitar el debate; la doxa se debe aceptar sin cuestionamiento para que cumpla la función de atenuar el deseo de cuestionar la arbitrariedad de los métodos y opciones de política que forman parte del habitus.

La doxa individualista y de libre mercado refleja estrechamente muchos aspectos esenciales de la cultura occidental más amplia, especialmente la de Estados Unidos, Reino Unido y otros países con fuerte herencia cultural anglosajona. Al irradiar su subcultura al resto del mundo, los economistas imponen a otros algunos elementos básicos de la cultura occidental con la apariencia de ciencia. Los economistas de los países en desarrollo formados en universidades occidentales o con manuales occidentales sirven como soldados rasos de la cultura occidental en sus países nativos. Los economistas respetados de Occidente usan modelos neoclásicos para juzgar las economías y las políticas económicas en todo el mundo. En suma, la mayoría de los economistas se comportan como los sociólogos occidentales que Bourdieu critica por juzgar las culturas extranjeras desde la óptica de su subcultura.

El ejemplo obvio de este sesgo en materia de economía es la tendencia a ocuparse exclusivamente de las actividades de mercado, a usar datos generados por los mercados y a interpretar los resultados como si toda actividad económica fuese emprendida por individuos racionales que actúan en mercados competitivos. Recordemos la cita de Bourdieu que encabeza este artículo. Por ello, gran parte de la investigación económica analiza actividades incluidas en el PIB medido, usa precios y cantidades de mercado para cuantificar la actividad económica e incluso usa precios de mercado como proxy del valor de la actividad externa al mercado cuando esta se incluye en el análisis. Por supuesto, se ignora y se da un valor implícito igual a cero a gran parte de la actividad externa al mercado, como la producción 
de los hogares y el trabajo voluntario ${ }^{3}$. Cualquier examen objetivo de la actividad económica del mundo real muestra que la mayoría de las interacciones económicas no ocurre entre individuos en mercados formales, sino entre personas que interactúan en una gran variedad de entornos distintos del mercado, en los hogares, en empresas de negocios, en interacciones voluntarias, en el gobierno y en diversas actividades colectivas.

Al mismo tiempo, la doxa neoliberal lleva a que muchos economistas consideren que temas como la felicidad psicológica, los problemas ambientales y la extinción de especies naturales son temas no económicos ajenos al campo de la economía. El estrecho alcance de la mayoría de las publicaciones profesionales refleja la conformidad del habitus de la economía con la doxa neoliberal que equipara la actividad económica con la actividad de mercado.

Un aspecto más importante de la cultura de la economía es que desalienta el estudio del comportamiento de grupo y del rol de las organizaciones en la sociedad. Por ello, a pesar de la abrumadora evidencia contraria proveniente de numerosos campos de la ciencia y la ciencia social, los economistas tradicionales usan casi exclusivamente funciones de bienestar que agregan el bienestar de individuos separables. Incluso después de dar el premio Nobel a economistas del comportamiento, como Kahnemann, Tversky y Akerlof, por estudiar los aspectos psicológicos de la actividad económica, y a economistas organizacionales, como Ostrom y Williamson, por estudiar los aspectos organizativos de la actividad económica, la mayoría sigue midiendo el crecimiento económico en términos de individuos que interactúan en los mercados. Así prestan poca atención al rol de grupos y organizaciones como los sindicatos, las grandes corporaciones y las grandes firmas financieras para explicar los resultados económicos. El poder de la cultura es enorme.

\section{LA VIOLENCIA SIMBÓLICA}

En efecto, la cultura no es solo un reflejo del paradigma dominante, también tiende a proteger ese paradigma de rivales que buscan un cambio de paradigma. Bourdieu $(1986,1989 b)$ explica que la cultura tiene un poder duradero porque explota el deseo personal de ser aceptado por el grupo. Las personas tienden consciente o incons-

${ }^{3}$ Economistas feministas como Waring (1988), Beneria (1992), Himmelweit (1995) y Folbre $(1996,2006)$ critican la economía tradicional porque ignora la actividad de los hogares como un importante contribuyente a la producción económica, y calculan que el valor de la actividad externa al mercado es del orden del PIB medido. 
cientemente a interpretar la realidad de maneras que a menudo las llevan a actuar contra sus propios intereses porque también valoran la aprobación social, la amistad y su rol en la sociedad y en su campo. Recordemos que el papel evolutivo de la cultura fue, al menos en parte, hacer posible el comportamiento individual que beneficia el bienestar de todo el grupo y no necesariamente de cada individuo. En numerosos casos la cultura puede ser opresiva.

En buena parte de su investigación, Bourdieu (1986, 1989a) se ocupó de la opresión cultural, que en su opinión era impulsada por la distribución desigual del capital cultural. Usó la palabra "capital" para describir la familiaridad de una persona con una cultura, y la facilidad para actuar dentro de ella refleja la acumulación de la cultura humana a través de largos y lentos procesos de educación, experiencia social, educación familiar, asimilación y aprendizaje.

Bourdieu describió diversas formas de capital cultural. Por ejemplo, el capital cultural heredado incluye comportamientos aprendidos como el conocimiento, los hábitos, el lenguaje y el dialecto, los manierismos sociales y la manera de conversar. Los economistas adquieren un conocimiento y una jerga distintivos. También existe el capital cultural objetivado, que incluye objetos físicos como un instrumento musical, la caja de herramientas de un carpintero o, en entre economistas, un computador y estantes de libros y publicaciones profesionales. En cada caso, el músico, el carpintero y los economistas perderían estatus si no poseyeran ese capital objetivado. Cabe señalar que el tamaño de la colección de publicaciones profesionales refleja la permanencia del economista en la profesión. Por último, el capital cultural institucionalizado incluye diplomas, premios, certificaciones y otras credenciales oficiales, cuya acumulación también requiere largo esfuerzo. Juntas, estas formas de capital cultural dan a quienes las poseen más poder de capital cultural sobre quienes poseen menos.

Bourdieu llama violencia simbólica al uso de este poder para imponer la voluntad propia a otra persona con menos capital cultural (1977b, 1986, 1989b, 2001). La discriminación y el hostigamiento son formas abiertas de violencia simbólica. Pero hay muchas formas sutiles de violencia simbólica, como el gesto o la mirada de desaprobación de un padre al hijo para que cambie su comportamiento o la expresión del jefe que dice al empleado que el "trabajo no está terminado" para señalarle que debe trabajar horas extras el fin de semana. La violencia simbólica entre adultos es esencial para perpetuar las desigualdades étnicas, de género y de edad. Bourdieu (2001) muestra que la violencia simbólica a menudo lleva a que las personas 
acepten lo que son, vistas objetivamente, injusticias, porque encajan en su doxa, para adaptarse al campo social que habitan. Documenta que los niños de clase trabajadora a menudo aceptan el orden social como algo legítimo y ven entonces el éxito educativo de sus pares de clase media y alta como un reflejo de la mayor capacidad o un arduo trabajo de estos últimos, y no como un privilegio social que les permitió adquirir los manierismos, el acento y la ropa asociada con los habitus de clases más altas.

Quienes se gradúan en economía en universidades de bajo rango, digamos en la Universidad de Nebraska, ven el éxito profesional de quienes se gradúan en universidades de rango más alto -como Harvard, el MIT, o la Universidad de California, en Berkeley- como un reflejo legítimo de la mayor capacidad de estos últimos o de su trabajo más arduo, aunque en realidad el capital cultural institucionalizado (los diplomas) rara vez es más que el resultado del capital cultural y del capital económico heredados. La presión económica, como la necesidad de ingreso o de un seguro de salud, a menudo lleva al trabajador a aceptar la doxa subyacente de jerarquía y la distribución existente del capital económico y cultural que justifica resultados económicos desiguales. Así, los doctorados en economía de Nebraska aceptan contratos de instructor por un año en universidades de nivel más bajo mientras que los de Harvard consiguen cargos que llevan a ser profesor permanente en universidades de rango más alto. De acuerdo con Bourdieu, las personas son cómplices de la violencia simbólica que experimentan porque ajustan inconscientemente su doxa para mantener su sentido de dignidad dentro de lo que se ven forzadas a aceptar como una realidad inmutable del campo social o profesional que habitan. La resignación ante el orden social existente se debe, según Bourdieu, a que la redistribución del capital cultural para reducir la violencia simbólica es un proceso gradual, difícil y lento, y a que quienes tienen más capital cultural suelen usarlo para oponerse a medidas redistributivas.

Un cambio de paradigma constituye un cambio del capital cultural. Intimidando a los portadores reales o potenciales de paradigmas alternativos, quienes han hecho grandes inversiones en el paradigma actual usan la violencia simbólica para proteger la doxa y el habitus contra hechos contradictorios o anomalias, como los llamó Kuhn (1962). Si las anomalías se discutieran y examinaran en forma abierta y objetiva sería más probable un cambio de paradigma. Pero dentro de la rígida cultura de la economía, pocos economistas cuestionarán sus modelos neoclásicos y mucho menos su doxa neoliberal. Pues 
recibieron una fuerte y continua aprobación por dominar la economía neoclásica de sus profesores en el posgrado, y después de graduarse siguen recibiendo afirmación implícita de la legitimidad de la doxa y el habitus por parte de colegas, editores de revistas y patronos. Como ilustración del carácter sutil de la violencia simbólica, consideremos por ejemplo un economista marxista a la espera de promoción y necesitado de aumentar sus publicaciones para justificar la promoción; muy bien podría convencerse de que es permisible que un marxista escriba un artículo basado en un modelo neoclásico estándar que refleja una estructura económica capitalista idealizada porque es más probable que sea publicado en una revista de "primera fila". Una justificación adicional sería que salvo que obtenga la promoción no podrá hacer un buen análisis económico marxista en el futuro. Entre tanto, no cuestiona el paradigma dominante.

En muchos campos intelectuales, como la economía, la violencia simbólica suele ser ejercida por los miembros más reputados que participan en los comités editoriales de las revistas profesionales y de las facultades, que contratan, promueven y despiden al profesorado. Así, a un joven profesor asistente que busca publicar y ser profesor permanente sus mentores le "darán el buen consejo" de escribir artículos que solo aplican el esquema neoclásico. El contenido de los cursos de los principales departamentos, la asesoría de tesis de grado y los criterios de selección para becas de investigación instalan la doxa y el habitus ortodoxos en la mente de los estudiantes que se convertirán en nuestros futuros economistas. Fuera de la academia, grupos de expertos financiados por corporaciones, la Reserva Federal de Estados Unidos y los bancos centrales de otros países, agencias internacionales como el FMI, el Banco Mundial y la OCDE, la prensa de negocios y las firmas financieras privadas también mantienen firmemente atrincherados los modelos neoclásicos y otros elementos del habitus de la economía mediante sus prácticas de empleo, su capacidad para influir en la política y en la prensa, y el dinero que financia investigaciones, publicaciones, becas, capacitación y filantropía.

\section{¿UNA DEFENSA DEL PLURALISMO?}

El anterior examen sociológico de la cultura de la economía sugiere que para estudiar seriamente las organizaciones y formas alternativas de comportamiento económico, los economistas deben encontrar una manera de liberarse de las restricciones impuestas por la cultura actual del campo. La cultura de la economía debe cambiar tanto su doxa neoliberal como su habitus neoclásico asociado. Como ya se 
indicó, la doxa del individualismo y la libre elección, que apoya las funciones de bienestar agregado bien establecidas en el habitus, no es solo técnicamente problemática para analizar las organizaciones o el comportamiento de grupo, sino que esa misma doxa, y el habitus que respalda, intimidan a los economistas para que se abstengan de ese análisis. Por ello, deben encontrar maneras de superar la violencia simbólica que emana de la cultura dominante.

Un breve examen de la historia del pensamiento económico, como el de la segunda sección, muestra que hay, de hecho, muchos enfoques alternativos que pueden ser útiles para entender nuestra compleja existencia económica. Algunos de los paradigmas alternativos disponibles para los economistas dispuestos a mirar por fuera de la cultura prevaleciente extenderían el análisis más allá de los límites de la economía de mercado; otros alentarían enfoques más integrales que incorporen los vínculos de la economía con las esferas social y natural de la existencia. Algunos economistas ya actúan con éxito fuera de las restricciones neoclásicas al pensamiento y la investigación. Por ejemplo, los economistas del comportamiento combinan la psicología y la economía para analizar asuntos económicos con modelos de comportamiento más realistas y medidas más completas del bienestar humano. Los economistas ecológicos y ambientales estudian las externalidades ambientales que los neoclásicos suelen ignorar. Los estudiosos de ciencia política y economía política plantean ideas valiosas sobre las causas y los efectos de las políticas económicas. Como ya se señaló, economistas feministas investigan las actividades de los hogares y de género en el lugar de trabajo para contrarrestar parte del análisis tradicional que se centra en el mercado y trata a los trabajadores como individuos homogéneos o "representativos" carentes de género, edad, clase, cultura y otras características históricas. Ganadores recientes del premio Nobel como Ostrom $(2005,2009)$ y Williamson $(1975,2002)$ han ido más allá del homo ceconomicus neoclásico para estudiar organizaciones de negocios, resultados de grupo y formas alternativas de acción económica colectiva que se pueden emprender en la sociedad. Los economistas institucionalistas han estudiado los grupos, las clases y el poder económico desde el siglo XIX, así como los economistas marxistas.

Una estrategia para lograr libertad paradigmática es empezar a reducir la violencia simbólica contra quienes abogan por paradigmas alternativos. La academia y otras organizaciones de investigación podrían dejar de discriminar a quienes no comparten la doxa y el habitus dominantes. Otra estrategia que ha tenido algún éxito es crear 
grupos de expertos alternativos; la New Economics Foundation, el Instituto Levy y el Instituto de Política Económica son ejemplos de centros de investigación dispuestos a abordar temas ajenos a la cultura dominante. Mejor aún, la profesión podría buscar el pluralismo y mantener paradigmas alternativos en su habitus. La concurrencia de paradigmas en el campo de la economía no solo haría posible que los nuevos paradigmas tengan una audiencia imparcial sino que, como señala Weehuizen (2007), evitaría que un nuevo paradigma y su doxa y su habitus opriman a futuros revolucionarios

\section{EL PODER ECONÓMICO RESPALDA LA VIOLENCIA SIMBÓLICA}

Ha sido muy difícil introducir la pluralidad de paradigmas en el campo de la economía. Como ya se dijo, la cultura actual de la economía es fuerte. Pero otra cosa es impedir el surgimiento de paradigmas alternativos: intereses económicos poderosos usan cada vez más la estructura del poder político para apoyar el paradigma dominante. Los economistas reflexivos deben enfrentar entonces algo más que la cultura de su campo.

Es interesante que el revolucionario Keynes (1936, viii) reconociera el poder de la cultura, como demuestra el prólogo de su Teoría General:

La redacción de este libro fue para el autor una larga lucha de escape, y así debe ser su lectura para la mayoría de los lectores para que el asalto del autor contra ellos tenga éxito: una lucha por escapar de los modos de pensamiento y expresión habituales. Las ideas que aquí se expresan tan laboriosamente son sumamente simples y deberían ser obvias. La dificultad radica no en las nuevas ideas sino en escapar de las viejas, que se ramifican en cada rincón de nuestra mente, pues con ellas nos educaron a muchos de nosotros.

Pero Keynes subvaloró el poder de la oposición activa a sus ideas por parte de los intereses comerciales y financieros. De hecho, sus nuevas ideas fueron casi inmediatamente diluidas para atenuar su choque con la cultura dominante en economía, como evidencia la obra de destacados economistas tradicionales como Hicks (1939) y Samuelson (1948). El rechazo intelectual de las ideas keynesianas fue alimentado por intereses comerciales y financieros opuestos a las políticas que pedía el paradigma keynesiano, como el New Deal de Roosevelt. Colander y Landreth (1996) muestran que antes de la aparición del manual de gran éxito comercial de Samuelson -con su ilógica combinación de un modelo macroeconómico keynesiano diluido con modelos microeconómicos neoclásicos tradicionales-, un libro de texto auténticamente keynesiano de Tarshis (1947) fue desterrado de las universidades de Estados Unidos por una campaña financiada por empresarios dirigida a fideicomisarios $y$ 
administradores universitarios. Los políticos también abandonaron el keynesianismo por presión de intereses comerciales y financieros conservadores. Por ejemplo, en 1937 el presidente Roosevelt revirtió algunas de sus políticas macroeconómicas de estímulo a instancia de líderes financieros y empresariales, pese a la advertencia expresa de sus propios economistas de que esto empujaría la economía de vuelta a la recesión. Por todo ello, en los años setenta las ideas de Keynes habían sido marginadas y las ideas neoclásicas retornaron al habitus del campo de la economía.

Hoy, individuos ricos y empresas y grupos financieros bien organizados ejercen su poder mediante relaciones públicas, publicidad y actividades de cabildeo muy costosas. "Invirtiendo" en la promoción de sus intereses, los grupos financieros privados han capturado a los principales partidos políticos en muchos países democráticos así como los medios noticiosos que informan al público sobre los debates y hechos políticos. Cuando estos medios buscan economistas para que comenten y opinen sobre temas económicos, la mayoría de las veces entrevistan economistas que trabajan para firmas comerciales o financieras, no para universidades independientes ni centros de investigación imparciales. Estos economistas comerciales y financieros casi siempre hacen eco a los temas del libre mercado, la desregulación y una mayor privatización, como si el paradigma neoclásico de individuos racionales que actúan en mercados de competencia perfecta representara nuestra realidad económica.

\section{CONCLUSIONES Y COMENTARIOS}

Con la doxa neoliberal firmemente arraigada, los economistas mantienen el homo ceconomicus racional en el centro de su análisis. Esto significa que están menos motivados para dedicarse a la investigación, la escritura o la enseñanza que revelen el poder de las organizaciones y de otras formas de comportamiento del grupo. En suma, poderosas organizaciones de cabildeo y defensa colaboran estrechamente con organizaciones de empresas privadas y entidades financieras para apoyar una cultura de grupo en el campo organizado de la economía que desalienta el estudio de esas organizaciones y formas de comportamiento social y de grupo. Así, las empresas transnacionales y los conglomerados financieros que dominan la economía global suelen volar bajo el radar mal orientado de la economía tradicional.

Esta conclusión nos recuerda las palabras de Robert Heilbroner, quien años atrás dijo que "el secreto mejor guardado en economía es 
que la economía es el estudio del capitalismo"4. Sin embargo, después de examinar la cultura de la economía, es claro que debemos revisar ligeramente la conclusión de Heilbroner: la economía es, de hecho, el estudio de un sistema mitico de mercado que tiene poca semejanza con el sistema capitalista global real en que vivimos. Eso no significa que la economía tradicional sea irrelevante. Desde dentro de ese mundo mítico pintoresco, los economistas generan un apoyo intelectual muy útil para la agenda de políticas neoliberales que favorece a las empresas y organizaciones financieras que han llegado a dominar el sistema económico real financiarizado y monopolizado. Por ello, los economistas tradicionales llevan una vida relativamente cómoda. Y la disfrutan libres de cualquier sentimiento de culpa porque su cultura pintoresca les asegura que la economía que hacen trata de la maximización del bienestar humano.

\section{REFERENCIAS BIBLIOGRÁFICAS}

1. Arrow, K. y G. Debreu. "Existence of an equilibrium for a competitive economy", Econometrica 22, 1954, pp. 265-290.

2. Benerfa, L. "Accounting for women's work: The progress of two decades”, World Development 20, 11, 1992, pp. 1547-1460.

3. Bourdieu, P. Outline of a theory of practice, Cambridge, Cambridge University Press, 1977a.

4. Bourdieu, P. "Symbolic power", D. Gleeson, ed., Identity and structure, Driffield, Nafferton Books, 1977b.

5. Bourdieu, P. "The forms of capital", J. G. Richardson, ed., Handbook of theory and research for the sociology of education, Nueva York, Greenwood Press, 1986.

6. Bourdieu, P. Homo academicus, Cambridge, Polity Press, 1988.

7. Bourdieu, P. La noblesse d'Etat: grands corps et grands écoles, París, Editions de Minuit, 1989a.

8. Bourdieu, P. "Social space and symbolic power", Sociological Theory 7, 1, 1989b, pp. 14-25.

9. Bourdieu, P. In other words: Essays toward a reflexive sociology, Stanford, Stanford University Press, 1990.

10. Bourdieu, P. Masculine domination, Cambridge, Polity Press, 2001.

11. Bourdieu, P. Science of science and reflexivity, Chicago, University of Chicago Press, 2005a.

12. Bourdieu, P. The social structures of the economy, Cambridge, U.K., Polity Press, 2005b.

13. Bourdieu, P. y L. Wacquant. An invitation to reflexive sociology, Chicago, University of Chicago Press, 1992.

14. Churchland, P. S. "Self-representation in nervous systems", Science 296, 5566, 2002, pp. 308-310.

15. Coase, R. "The problem of social costs", Journal of Law and Economics 3, 1, 1960, pp. 1-44.

${ }^{4}$ Citado en Palley $(1998,15)$. 
16. Colander, D. y H. Landreth. The coming of Keynesianism to America, Brookfield, Vermont, Edward Elgar, 1996.

17. Debreu, G. Theory of value, New Haven, CN, Yale University Press, 1959.

18. Fama, E. "Efficient capital markets: A review of theory and empirical work", Journal of Finance 25, 3, 1970, pp. 383-417.

19. Folbre, N. "Children as public goods", American Economic Review 84, 2, 1994, pp. 86-90.

20. Folbre, N. "Measuring care: Gender, empowerment, and the care economy", Journal of Human Development 7, 2, 2006, pp. 183-199.

21. Frederick, S. "Cognitive reflection and decision-making", Journal of Economic Perspectives 19, 4, 2005, pp. 25-42.

22. Friedman, M. "The case for flexible exchange rates", M. Friedman, ed., Essays on positive economics, Chicago, University of Chicago Press, 1953, pp. 157-203.

23. Harvey, D. A brief history of Neoliberalism, Nueva York, Oxford University Press, 2005.

24. Hicks, J. R. "Mr. Keynes and the classics”, Econometrica 5, 2, 1937, pp. 147-159.

25. Himmelweit, S. "The discovery of 'unpaid work': The social consequences of the expansion of work", Feminist Economics 1, 2, 1995, pp. 1-19.

26. Jensen, M. y W. Meckling. "Theory of the firm: Managerial behavior, agency costs and ownership structure", Journal of Financial Economics 3, 4, 1976, pp. 305-360.

27. Keynes, J. M. The general theory of employment, interest, and money [1936], Nueva York, Harcourt Brace Jovanovich, 1964.

28. Kuhn, T. The structure of scientific revolutions, Chicago, University of Chicago Press, 1962.

29. Langlois, R. "Coherence and flexibility: Social institutions in a world of radical uncertainty", I. Kirzer, ed., Subjectivism, intelligibility, and economic understanding: Essays in honor of the eightieth birthday of Ludwig Lachmann, Nueva York, New York University Press, 1986, pp. 171-191.

30. Langlois, R. "Orders and organizations: Toward an Austrian theory of social institutions", B. Caldwell y S. Bohm, eds., Austrian economics. Tensions and new directions, Dordrecht, Kluwer Academic Publishers, 1992.

31. Leboeuf, R. A. "Alternating selves and conflicting choices: Identity salience and preference inconsistency", Dissertation Abstracts International 63(2-B), 2002, p. 1088.

32. Lucas, R. E. "Expectations and the neutrality of money", Journal of Economic Theory 4, 1, 1972, pp. 103-124.

33. Marshall, A. Principles of economics [1920], $8^{\text {th }}$ ed., Londres, MacMillan, 1959.

34. Medin, D. y M. Bazerman. "Broadening behavioral decision research: Multiple levels of cognitive processing", Psychonomic Bulletin and Review 6, 4, 1999, pp. 533-47. 
35. Muth, J. F. "Rational expectations and the theory of price movements", Econometrica 29, 1961, pp. 315-335.

36. North, D. C. Understanding the process of economic change, Princeton, NJ, Princeton University Press, 2005.

37. Ostrom, E. Understanding institutional diversity, Princeton, NJ, Princeton University Press, 2005.

38. Ostrom, E. "A general framework for analyzing sustainability of social-ecological systems”, Science 325, 5939, 2009, pp. 419-422.

39. Palley, T. Plenty of nothing: The downsizing of the American dream and the case for structural Keynesianism, Princeton, Princeton University Press, 1998.

40. Samuelson, P. Economics, Nueva York, McGraw-Hill, 1948.

41. Seabright, P. The company of strangers: A natural history of economic life, $2^{\text {nd }}$ ed., Princeton, NJ, Princeton University Press, 2010.

42. Simon, H. "A behavioral model of rational choice", Quarterly Journal of Economics 69, 1955, pp. 99-118.

43. Simon, H. "Theories of decision-making in economics and behavioral science", American Economic Review 49, 1959, pp. 253-283.

44. Smith, A. An inquiry into the nature and causes of the wealth of nations [1776], Chicago, University of Chicago Press, 1976.

45. Tarshis, L. The elements of economics, Boston, Houghton Mifflin, 1947.

46. Unesco. "Universal declaration of cultural diversity", 2002, [www. unesco.org].

47. Wacquant, L. "Toward a reflexive sociology: A workshop with Pierre Bourdieu", Sociological Theory 7, 1, 1989, pp. 26-63.

48. Wacquant, L. Punishing the poor: The neoliberal government of social insecurity, Durham, NC, Duke University Press, 2009.

49. Walras, L. Eléments d'économie politique pure, ou théorie de la richesse sociale, 1874.

50. Waring, M. If women counted: A new feminist economics, San Francisco, Harper \& Row, 1988.

51. Weber, M. Economy and society, Berkeley, University of California Press, 1978.

52. Weehuizen, R. "Interdisciplinary and problem-based learning in economics education: The case of infonomics", J. Groenewegen, ed., Teaching pluralism in economics, Northampton, MA, Edward Elgar, 2007, pp. 155-188.

53. Williamson, O. Markets and hierarchies: Analysis and anti-trust implications, Nueva York, Free Press, 1975.

54. Williamson, O. "The theory of the firm as governance structure: From choice to contract", Journal of Economic Perspectives 16, 3, 2002, pp. 171-195. 